\title{
CITOLOGIA DE LAVADO BRONCOALVEOLAR DE CÃES: COMPARAÇÃO ENTRE LÂMINAS A FRESCO E CONSERVADAS EM FORMOL
}

\author{
Cristina Rauen Ribas ${ }^{1}$, Peterson Triches Dornbusch², Silvana Maris Cirio², \\ Rita Maria Venâncio Mangrich Rocha ${ }^{1}$, Luiz Guilherme Achcar Capriglione ${ }^{1}$, \\ Ana Laura Pinto D'Amico Fam ${ }^{1}$ \\ 1 Pontifícia Universidade Católica do Paraná, Curitiba/PR - ribas-cr@bol.com.br \\ 2 Universidade Federal do Paraná
}

\begin{abstract}
RESUMO: O lavado broncoalveolar em cães é um método diagnóstico recomendado em casos de enfermidades do trato respiratório inferior, quando exames de rotina não permitem um diagnóstico conclusivo. O exame baseia-se na análise citológica e confecção de lâminas com o material a fresco, ou seja, logo após a coleta, o que pode inviabilizar a técnica em casos de difícil acesso aos laboratórios especializados. Para isso, faz-se necessário um meio de conservação das amostras, aumentando o tempo de vida útil do material a ser analisado. Assim, realizou-se o lavado broncoalveolar em quatorze cães adultos saudáveis. As amostras foram separadas em duas alíquotas: a primeira confeccionada a fresco por sedimentação em câmara de Suta, e a segunda processada uma semana depois, com a amostra conservada em formol. As lâminas foram coradas pelo corante rápido Panótico. Avaliou-se o volume infundido e o volume recuperado, o aspecto macroscópico, a contagem de células nucleadas, a análise diferencial de células e a análise descritiva das lâminas quanto à celularidade, presença de muco, hemácias, leucócitos e células, íntegras ou degeneradas. A análise estatística foi realizada com teste t, para amostras pareadas com $p<0,05$. Foram encontrados aumento significativo na quantidade de linfócitos e diminuição do número de macrófagos nas amostras conservadas em formol. As demais observações foram similares em ambos os grupos. Portanto, a conservação do material do lavado broncoalveolar de cão em formol, durante uma semana, preservou as células, tornando viável a técnica do lavado broncoalveolar.
\end{abstract}

Palavras-chave: citologia; cão; formol; lavado broncoalveolar

\section{CYTOLOGY OF BRONCHOALVEOLAR LAVAGE OF DOGS: COMPARISON AMONG LAMINA TO FRESH AND CONSERVED IN FORMOL}

\begin{abstract}
The bronchoalveolar lavage in dogs is a diagnostic method recommended in cases of illnesses of the caudal respiratory tract, when routine exams do not allow a diagnosis. The exam relies on the cytological analysis and fresh smear immediately after sampling, which may difficult the adequate processing at the specialized laboratories. Accordingly, a sample conservation media which increases the material time span to be analyzed would be desirable. In the present study, bronchoalveolar lavage was performed in fourteen healthy adult dogs. Samples were separate in two aliquots: one freshly made by in chamber of sedimentation, and another processed one week later, with the sample preserved in formalin. Slides were stained by quick Romanovsky-type stain (Panótico Rápido $^{\circledR}$, Laborclin ${ }^{\circledR}$, Pinhais, Brazil). The infused volume, the recovered volume, the macroscopic aspect, the counting of nucleated cells, the differential cell analysis and the smear descriptive analysis such as cellularity, mucus presence, erythrocytes, leukocytes and degenerate cells were evaluated. The statistical analysis was performed with $T$ test, for paired samples with $p<0.05$. Significant increase was found in the amount of lymphocytes and decrease of the macrophage numbers in formalin preserved samples. All other observations were similar in both groups. Therefore, the preservation of the bronchoalveolar lavage sample of dogs in formalin, during one week, preserved the cells, making the bronchoalveolar lavage technique routinely feasible.
\end{abstract}

Key words: bronchoalveolar lavage; dogs; formalin; cytology 


\section{INTRODUÇÃO}

As alterações pulmonares representam $4 \%$ dos casos na rotina da clínica médica de pequenos animais (Ferian et al., 2006). Geralmente, as doenças respiratórias são de difícil diagnóstico e necessitam de exames complementares, como: hemograma, bioquímica, hemogasometria, sorologia, exames radiográficos, análise de fluidos das vias aéreas e biopsia pulmonar (Corcoran, 2004; Ferian et al., 2006). O lavado broncoalveolar (BAL), exame citológico do fluido aspirado da árvore brônquica, pode auxiliar na avaliação das doenças do trato respiratório (Hodgson, 2003; Erickson e Poole, 2003). O lavado bronco alveolar (BAL) é - método de seleção utilizado para examinar as vias aéreas distais, devido à sua eficácia na avaliação do meio celular dentro de um segmento de brônquio, bronquíolo e alvéolos, quando a anamnese, o exame físico e outros exames complementares não foram efetivos em estabelecer um diagnóstico definitivo (Forgarty e Buckley, 1991; Clark, et al., 1995; Erickson e Poole, 2003; Nelson e Couto, 1994). Trata-se de um método rápido e prático, cujas condições de armazenamento e processamento em laboratório devem ser adequadas, para manter a viabilidade da amostra e produzir resultados de alta acurácia. Segundo, Fernandes et al. (2000) o BAL teve sua técnica originária da medicina e depois adaptada para veterinária, sendo mais difundida na medicina de equinos. $\mathrm{Na}$ medicina de pequenos animais, De Mello e Ferreira (2003) afirmam que o tempo de conservação do fluído broncoalveolar é variável, no entanto o período do processamento além de 24 horas após a colheita pode resultar em alterações e erros de interpretação.

Os objetivos deste estudo foram comparar a qualidade citológica e as diferenças nas contagens celulares entre amostras a fresco e amostras conservadas em formol, obtidas a partir do lavado broncoalveolar de cães.

\section{MATERIAL E MÉTODOS}

Foram utilizados quatorze cães adultos, sem raça definida, 6 machos e 8 fêmeas, com pesos até $25 \mathrm{~kg}$ e idade média de $5,3 \pm 2$ anos. Todos os animais estavam clinicamente e laboratorialmente saudáveis mantidos em abrigo da região metropolitana de Curitiba, Estado do Paraná. Os cães foram mantidos em gaiolas um dia antes do procedimento, onde foram alimentados com ração comercial seca, e água ad libitum e posteriormente submetidos a jejum alimentar de 12 horas.

Exames clínicos e laboratoriais foram realizados no primeiro dia, logo após a chegada dos animais. Foram avaliados: a freqüência respiratória (FR), a frequência cardíaca (FC), o estado de hidratação, a coloração de mucosas, o tempo de preenchimento capilar (TPC), os linfonodos, a temperatura retal (TR), o estado de alerta, além dos sistemas cardiovasculares, respiratórios, tegumentares, gastrointestinais, urinários, reprodutivos, neurológicos e locomotores. Os animais foram examinados, ainda, através de ultra-sonografia abdominal e exames laboratoriais: hemograma, bioquímicos (uréia, creatinina, fosfatase alcalina, alanina-aminotransferase ou ALT, albumina e proteína total), coagulograma (tempo de protrombina ou TP, tempo de tromboplastina parcial ativada ou TTPA e contagem de plaquetas), urinálise e coproparasitológico.

Para a realização do lavado, os animais foram sedados com acepromazina, na dose de $0,05 \mathrm{mg} / \mathrm{kg} / \mathrm{lM}$ e em seguida foi induzida anestesia de curta duração com propofol, na dose de 5 $\mathrm{mg} / \mathrm{kg} / \mathrm{IV}$. Na sequência o paciente foi 
entubado com sonda traqueal apropriada. Após a indução anestésica e 5 minutos de pré-oxigenação, foi inserida no interior do traqueotubo uma sonda de alimentação enteral siliconizada, calibre 12, adaptada pelos autores, através da remoção da extremidade de látex, mantendo 0 mandril metálico flexível durante todo o procedimento, até encontrar resistência provavelmente na árvore brônquica (brônquios, bronquíolos e alvéolos). Infundiu-se $20 \mathrm{ml}$ de solução fisiológica comercial $0,9 \%$ e, logo em seguida, $5 \mathrm{ml}$ de ar, a fim de evitar resquícios dessa solução na sonda. Imediatamente, aspirou-se a solução infundida por sucção, em seringa devidamente identificada, com o mandril metálico trançado, para evitar o colabamento do lúmen durante a aspiração. Caso o volume inicialmente infundido fosse insuficiente, repetia-se o procedimento. Concluída a aspiração da amostra, o animal foi mantido em oxigenioterapia durante 15 minutos, enquanto recuperava-se do procedimento anestésico, tempo adequado para o animal mudar o decúbito para esternal e, até mesmo, levantar. O conteúdo aspirado foi encaminhado imediatamente ao Laboratório de Patologia Clínica, onde foi separado em duas alíquotas: uma fresca foi avaliada em um intervalo máximo de uma hora após a aspiração; a outra, armazenada em tubos de ensaio fechados durante 7dias, com uma gota de formol, para cada $\mathrm{ml}$ de lavado, foi processada e avaliada no sétimo dia. A avaliação citológica do fluido broncoalveolar foi realizada de forma quantitativa, por contagem relativa em percentual, e qualitativa. Primeiramente, avaliou-se a proporção do volume infundido e do volume aspirado. E, logo após, as características macroscópicas do aspirado, como: coloração, aspecto e turbidez, e as características microscópicas do aspirado, como: a contagem de células nucleadas, a análise celular diferencial e análise descritiva da lâmina. A contagem de células nucleadas foi realizada com o auxílio de Câmara de Neubauer e microscópio óptico, sem sedimentação prévia da amostra, sendo contadas as células presentes nos quadrantes das extremidades. O total de células contadas era multiplicado por 2,5; obtendo assim, o valor de células nucleadas totais da amostra. As demais características microscópicas foram analisadas após a técnica de sedimentação, onde $1 \mathrm{~mL}$ do fluído foi submetido, em Câmara de Suta (Figura 1), por 1 hora, para o processamento da lâmina do BAL. Após esse período, o líquido excedente foi desprezado e a fixação feita por secagem rápida por agitação ao ar durante um período máximo de 30 minutos. Com o BAL seco, o botão celular contido na lâmina,

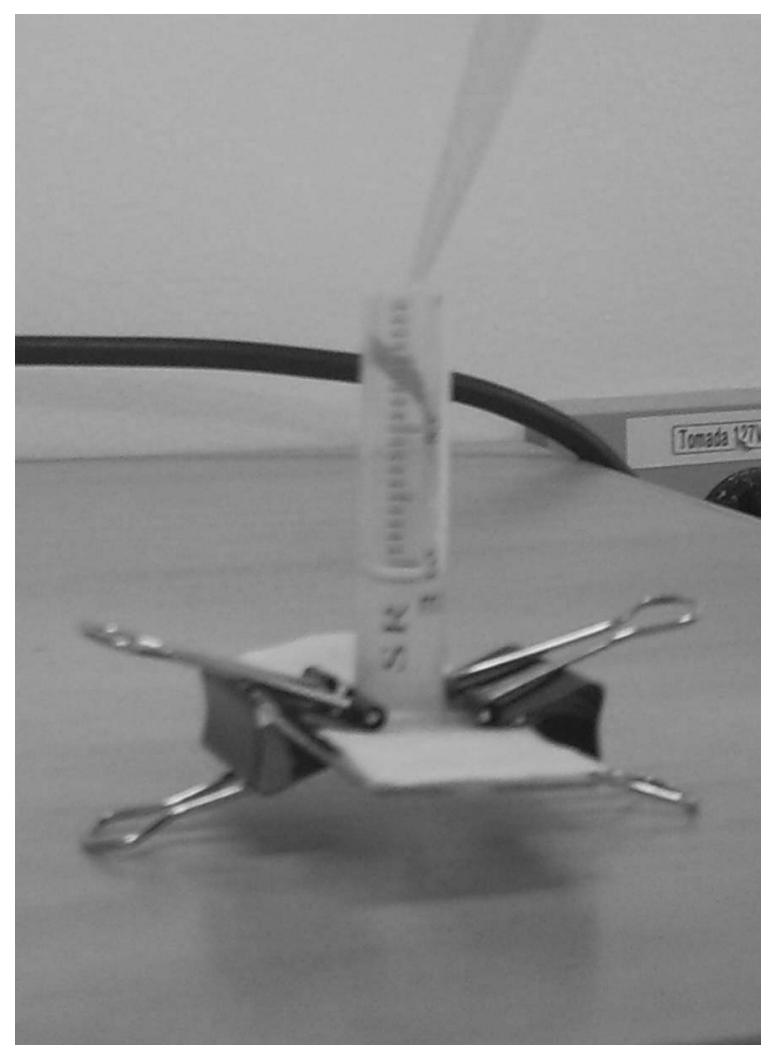

Figura 1 - Sistema de sedimentação em Câmara de Suta, onde as amostras foram mantidas durante uma hora, para a confecção das lâminas. 
foi corado pela técnica de Panótico Rápido, para a análise celular diferencial de um total de 400 células, diferenciando-se as proporções de macrofagos, neutrófilos, linfócitos, eosinófilos, mastócitos, células epiteliais e hemosiderófagos. Avaliou-se, como análise descritiva das lâminas, a celularidade, a presença de muco, a presença de hemácias, e a presença de células íntegras ou degeneradas aglomeradas ou não. Para minimizar os erros na avaliação do fluído broncoalveolar na avaliação microscópica foram realizadas análises em pares, ou seja, cada amostra foi avaliada duas vezes, antes mesmo de se obter os resultados percentuais finais.

A quantidade de muco nas lâminas foi classificada em: Grau 1 - ausente: Grau 2 - pouco; Grau 3 - moderado; Grau 4 - grande quantidade. Para clas sificação da qualidade das células foi proposto um escore de lâminas, classificadas da seguinte forma: Grau 1células não preservadas; Grau 2identificadas com dificuldade e com perda de citoplasma; Grau 3identificadas com dificuldade, mas com citoplasma preservado; Grau 4- fácilmente identificadas.

Para a distribuição das células sobre as lâminas foi criado um escore visual, onde: Grau 1 - raras; Grau 2 poucas e espaças; Grau 3 - boa distribuição; Grau 4 - muitas células por campo; Grau 5 - células aglomeradas e sobrepostas.

Para a análise estatística foi utilizado o software GraphPad Prism $v .5$, e o teste $t$, com nível de significância de $5 \%(p<0,05)$. Para os dados do escore visual do muco foi utilizado o teste de Wilcoxon, para as amostras pareadas e Mann-Whitney para dados não paramétricos, ambos com nível de significância de $5 \%$ $(\mathrm{P}<0,05)$.

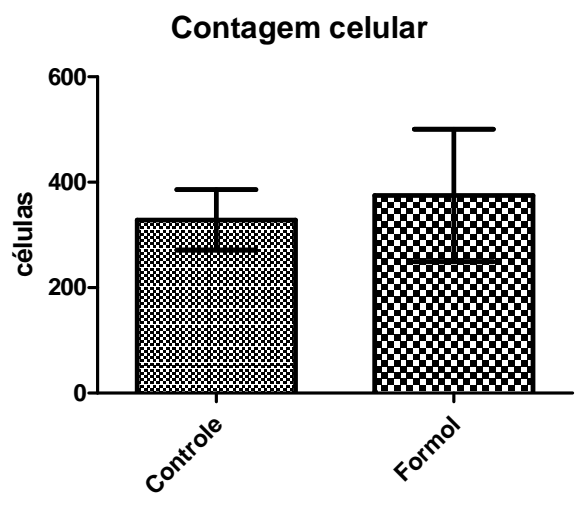

Figura 2 - A média da contagem celular por decilitro, das amostras do BAL com e sem formol, em cães saudáveis, onde $p>0,05$, em relação ao grupo controle. As barras indicam as médias e o desvio padrão.

\section{RESULTADOS}

$O$ volume infundido foi padronizado em 20 mililitros $(\mathrm{mL})$ para todos os animais, porém em apenas um animal foi preciso repetir o procedimento. $\mathrm{O}$ volume médio aspirado foi de $7,25 \mathrm{~mL}$, sendo que a menor quantidade obtida em um animal foi de $2 \mathrm{~mL}$.

A contagem celular das amostras do BAL a fresco e conservado em formol não diferiu significativamente, mostrando-se efetivo o pareamento entre as amostras (Figura 2).

A avaliação da contagem diferencial de células está demonstrada na Tabela 1. A contagem diferencial de neutrófilos, eosinófilos, mastócitos, células epiteliais e hemosiderófagos, não diferiu significativamente entre as amostras. Entretanto, as médias das contagens de macrófagos e linfócitos diferiram significativamente entre as lâminas citológicas confeccionadas com e sem formol.

A avaliação do escore de muco observado nas lâminas citológicas apresentou um pareamento similar, sendo que as médias não apresentaram diferença significativa, como pode ser verificado na Figura 3. 
Tabela 1 - Contagem diferencial realizada através da técnica de sedimentação das amostras a fresco versus as amostras conservadas em formol, em animais clinicamente saudáveis

\begin{tabular}{ccc}
\hline & \multicolumn{2}{c}{ Contagem Diferencial (\%) } \\
\cline { 2 - 3 } Tipo Celular & Amostra com Formol & Amostra fresca (controle) \\
\hline Macrófagos & $79,04 \pm 6,26^{*}$ & $88,54 \pm 6,06$ \\
Neutrófilos & $0,73 \pm 0,47$ & $1,11 \pm 0,85$ \\
Linfócitos & $17,30 \pm 6,22^{*}$ & $8,39 \pm 5,85$ \\
Eosinófilos & 0 & $0,04 \pm 0,09$ \\
Mastócitos & $0,14 \pm 0,23$ & $0,16 \pm 0,25$ \\
Células Epiteliais & $3,21 \pm 2,59$ & $2,14 \pm 2,56$ \\
Hemossiderófagos & & $5,69 \pm 2,49$ \\
(\% macrófagos) & $7,62 \pm 5,41$ &
\end{tabular}

${ }^{*} \mathrm{P}<0,05$ em relação ao grupo controle.

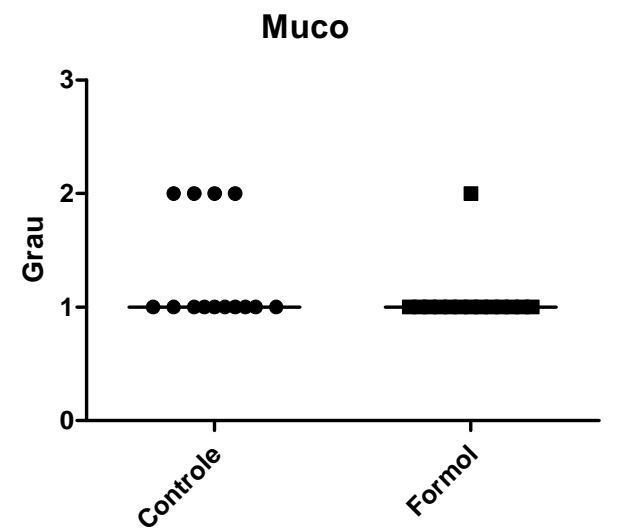

Figura 3 - Escore de presença de muco observado nas lâminas confeccionadas com e sem formol, em cães saudáveis. As barras indicam a mediana.

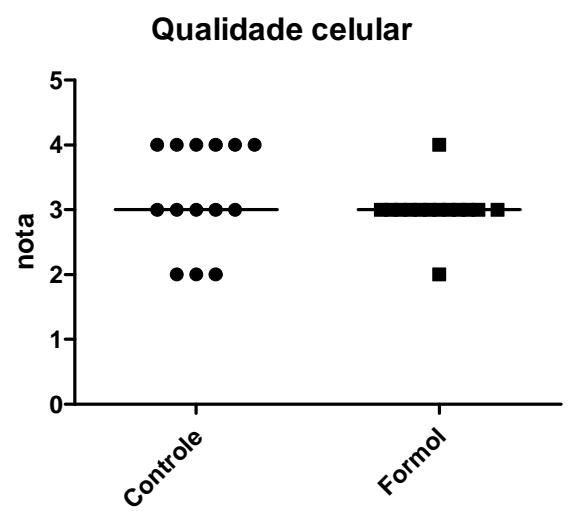

Figura 4 - Escore de qualidade de preservação celular observado nas lâminas confeccionadas com e sem formol, em cães saudáveis. As barras indicam a mediana.

A qualidade da preservação celular nas lâminas citológicas, assim como a distribuição celular não demonstrou diferenças entre os grupos (Figuras $4 \mathrm{e}$ $5)$.

\section{DISCUSSÃO}

Embora o procedimento do BAL esteja padronizado e frequentemente utilizado em equinos, em cães, sua técnica ainda sofre muitas variações, e pode ser adaptada conforme cada experimento, visando encontrar o método mais adequado. Neste estudo, foi realizada a infusão de $20-40 \mathrm{~mL}$, o que variou em torno de 1,43 a 2,86 $\mathrm{mL}$ por $\mathrm{kg}$ de peso vivo, diferente do realizado por De Mello e Ferreira (2003), com $5 \mathrm{~mL} / \mathrm{kg}$ e por Andreasen (2003), que utilizou um volume de $50 \mathrm{~mL}$, que chamou de pequeno volume e um grande volume de $500-600 \mathrm{~mL}$. Andreasen (2003), então, sugere que de acordo com o volume infundido para a realização do BAL, tem-se uma contagem celular diferenciada. Mansmann e King (1998) afirmam que após a padronização do procedimento do BAL, cujo volume infundido em todos os animais torna-se constante, há um critério de infusão, e com isso uma maior acurácia dos resultados.

No presente estudo a técnica do $\mathrm{BAL}$, de avaliação citológica do trato inferior canino, com ou sem conservação através de formol, se mostrou muito eficiente sendo mais uma ferramenta para o clínico veterinário. 


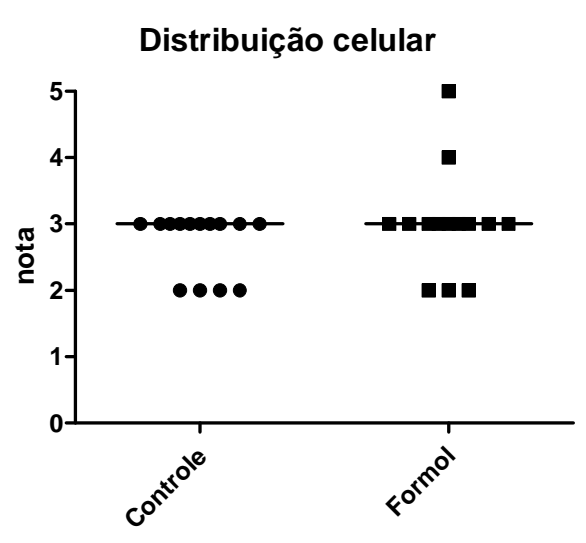

Figura 5 - Escore de distribuição celular observado nas lâminas confeccionadas com e sem formol, em cães saudáveis. As barras indicam a mediana.

Basso et al. (2008) verifica que no $\mathrm{BAL}$ as células de prevalência em animais clinicamente sadios são os macrófagos alveolares, devido à localização do fluido nas pequenas vias aéreas e alvéolos, assim como o encontrado neste estudo. Na sequência, são encontradas populações celulares de linfócitos, neutrófilos, células epiteliais, mastócitos e eosinófilos, concordando também, com Andreasen (2003) e Melchert et al. (2008).

Andreasen (2003) ressalta que a contagem celular varia conforme 0 volume infundido, onde em um volume de $50 \mathrm{~mL}$ há maior quantidade de neutrófilos e células bronquiais; enquanto que no volume de 500-600 $\mathrm{mL}$, os macrófagos alveolares possuem uma ocorrência de $80 \%$. Possivelmente, esse efeito é devido a diferenças no comprimento e diâmetro das sondas utilizadas, pois quando se realiza 0 lavado através de sondas traqueais, com pequeno volume, acaba-se realizando um lavado traqueal, onde o predomínio é neutrófilos. Neste estudo os dados obtidos foram diferentes, pois mesmo utilizando um volume infundido menor do que o de Andreasen (2003), encontrou-se uma prevalência de macrófagos alveolares, o que confirma o posicionamento da sonda profundamente nas vias aéreas.
Uma pequena quantidade de muco, como vista neste estudo, pode estar presente em animais clinicamente sadios. No entanto, aspectos granulares do muco, frequentemente estão associados ao aumento da celularidade; ou seja, em casos de reação inflamatória, ocorre maior produção de muco e com isso, incorporação das proteínas inflamatórias e de materiais pós-lise celular (Cowell et al. 1999).

Segundo Biava et al. (2005) e Martín Juan (1994), avaliações do BAL realizadas em citocentrífuga resultam em menor número de linfócitos, devido ao processamento. Neste estudo observou-se diminuição na contagem de macrófagos nas amostras conservadas em formol, o que acarretou um aumento na contagem das demais células, especialmente dos linfócitos, dados que diferiram dos encontrados por Basso et al. (2008), sugerindo que as células do BAL conservadas em formol possam exercer efeito deletério sobre os macrófagos.

Os hemosiderófagos são macrófagos alveolares, que fagocitam eritrócitos, os quais podem indicar congestão pulmonar, edema pulmonar, reação inflamatória com danos à barreira alvéolo-capilar e processos neoplásicos; os quais podem ser confundidos com pigmentos escuros como: melanina e carbono, em casos de antracose pulmonar (Andreasen, 2003). A quantidade é variável para cada indivíduo, e os valores limites não são descritos na literatura. Neste estudo, com animais de abrigo, é possível encontrar alterações subsequentes ao ambiente por eles habitado, contendo agentes químicos e biológicos capazes de provocar hemorragias visualizadas no BAL.

Carvalho et al. (2004) em um estudo do BAL em humanos, condicionou suas amostras em banho de gelo, para serem encaminhadas imediatamente ao laboratório; sugerindo 
um curto tempo de conservação da amostra neste meio. A Agência Nacional de Vigilância Sanitária (ANVISA, 2000), na medicina, estabelece que uma amostra de fluido de lavado broncoalveolar deve ser analisada em no máximo 2 horas, após a coleta. Porém na veterinária, especialmente nos equinos, estes prazos variam até 48 horas em temperatura ambiente, até 24 horas em temperatura de $0-4^{\circ}$.C e ultrapassa as 24 horas, quando adicionadas substâncias fixadoras (Pickles et al., 2002; McGorum e Dixon, 1994). De Mello e Ferreira (2003), em pequenos animais, estabelecem um período de conservação variável, independentemente da temperatura de armazenamento, mas sugerem que 0 processamento após 24 horas pode resultar em alterações significativas. Levando em conta a redução na quantidade de macrófagos e o aumento proporcional de linfócitos no armazenamento das amostras em formol como sugerido no estudo, o meio de conservação utilizado, foi capaz de manter a viabilidade do BAL por uma semana, permitindo desta forma identificar alterações celulares presentes, desde que o laboratório tenha padronizado a leitura para este tipo de amostra.

\section{CONCLUSÃO}

A técnica de conservação da amostra do lavado broncoalveolar em cães por formol, durante uma semana, foi eficiente em manter viável o material para confecção de lâminas citológicas.

A interpretação da contagem celular diferiu significativamente apenas na proporção entre macrófagos e linfócitos nas amostras. Desta forma, estabelecendo os valores de referência, é possível utilizar o formol como meio de conservação do lavado broncoalveolar de cães, por até uma semana, em casos onde não haja possibilidade de processar a amostra a fresco.

\section{NOTA INFORMATIVA}

O projeto de pesquisa foi aprovado pelo Comitê de Ética de uso de animais, protocolo n359.

\section{REFERÊNCIAS}

ANDREASEN, C.B. Bronchoalveolar lavage. The Veterinary Clinics Small Animal Pratice, v.33, p.69-88, 2003.

BASSO, P.C. Lavado traqueobrônquico auxiliado por endoscópio rígido ou por tubo endotraqueal em cães, Ciência Rural, v.38, n.3, p.723-728, 2008.

BIAVA, J.S; GONÇALVES, R.C.; ZANOTTO, G.M. et al. Uso da citocentrífuga e colorações especiais no exame citológico do lavado broncoalveolar em cavalos. Revista

Acadêmica, v.3, n.4, p. 47-50, 2005.

CARVALHO, J.E.M.de; MORAES, I.N.; FERREIRA, A.S. et al.Estudo do lavado broncoalveolar em pacientes com comprometimento pulmonar na leptospirose. Jornal Brasileiro de Pneumologia, v.30, n.2, p.134-139, 2004.

CLARK, C.K.; LESTER, G.D.; VETRO, T. et al. Bronchoalveolar lavage in horses: effect of exercise and repeated sampling on cytology. Australian Veterinary Journal, v.72, p.249252, 1995.

CORCORAN, B. Avaliação clínica do paciente com doença respiratória. In: ETTINGER, S.J.; FELDMAN, E.C. Tratado de Medicina Interna Veterinária. Doenças do cão e do gato. 5. ed. São Paulo: Ed. Guanabara Koogan, 2004. p.1090-1096.

COWELL, R.L.; TYLER, R.D.; BALDWIN, C.J. et al. Transtracheal/ Bronchoalveolar Washes. In: COWELL, R.L. et al. Diagnostic Cytology and Hematology of the Dog and Cat. 2. ed. USA: Mosby publishing, 1999. p.159-173.

DE MELLO, M.F.V.; FERREIRA, A.M.R. Análise citológica do líquido de lavagem broncoalveolar para o diagnóstico das doenças pulmonares caninas - revisão. Clínica Veterinária, n.42, p.52-8, 2003.

ERICKSON, H.H.; POOLE, D.C. Exerciseinduced pulmonary hemorrhage. In: Equine Respiratory Disease. Ithaca, NY: International 
Veterinary Information Services. <disponível em: www.ivis.org > Acesso em 2005.

FERIAN, P.E.; SILVA, E.F.; GUEDES, R.C. et al. Diagnóstico citológico de neoplasia pulmonar por meio de lavado broncoalveolar em uma cadela: relato de caso. Arquivo Brasileiro de Medicina Veterinária e Zootecnia, v.58, n.5, p.776-780, 2006.

FERNANDES, W.R.; MORI, E.; SANCHES, A. Avaliação citológica de lavados traqueobrônquicos e broncoalveolar em cavalos clinicamente sadios pelo método de coloração de Rosenfeld. Arquivo Brasileiro de Medicina Veterinária e Zootecnia, v.52, n.6, 2000.

FORGARTY, U.; BUCKLEY, T. Bronchoalveolar lavage findings in horses with exercise intolerance. Equine Veterinary Journal, v.6, p. 434-437, 1991.

HODGSON, D.R.; HODGSON, J.L. Comparison of tracheal aspirates and bronchoalveolar lavage in racehorses 1. Evaluation of cytological stains and the percentage of mast cells and eosinophils. Australian Veterinary Journal, v.81, n.11, p.681-684, 2003.

MANSMANN, R.A.; KING, C. How to perform Bronchoalveolar Lavage in practice. Ithaca, NY: International Veterinary Information Service, 1998. 186p.
MARTíN JUAN, J. Guia de Procedimentos Lavado Broncoalveolar. Neumosur: Revista de La Asociación de Neumólogos Del SUR, v.6, n.2, p.34-39, 1994.

McGORUM, B.C.; DIXON, P.M. The analysis and interpretetaion of equine bronchoalveolar lavage fl uid (BALF) cytology. EquineVeterinary Education, v.6, n.4, p.203-209, 1994.

MELCHERT, A.; MOTTA, Y.P.da; GIUFFRIDA, R. et al. Avaliação citológica e microbiológica do lavado broncoalveolar em cães hígidos.

Ciências Agrárias, v.29, n.1, p.157-164, 2008.

MINISTÉRIO DA SAÚDE - ANVISA. Manual de procedimentos básicos em microbiologia clínica para o controle de infecção hospitalar - Modulo I. Brasília: ANVISA, 2000. 51p.

NELSON, R.W.; COUTO, C.G. Testes Diagnósticos para o Trato Respiratório Inferior. In: . Fundamentos de Medicina Interna de Pequenos Animais. Califórnia: Ed. Guanabara Koogan, 1994. p.137-152.

PICKLES, K.; PIRIE, R.S.; RHIND, S. et al. Cytologycal analysis of equine bronchoalveolar lavage fluid. Part 3: the effect of time, temperature and fixatives. Equine Veterinary Journal, v.34, n.3, p.297-301, 2002. 